SLUCKIN, W. Imprinting and early learning. London: Methuen, 1964.

SLUCKIN, W. Imprinting in guinea-pigs. Nature, $1968,220,1148$.

TAYLOR, A., SLUCKIN, W., HEWITT, R., \& GUITON, P. The formation of attachments by domestic chicks to two textures. Animal Behaviour, 1967, 15, 514-519.

TAYLOR, A., SLUCKIN, W., \& HEWITT, R.
Changing colour preferences in chicks. Animal Behaviour, 1969, 17, 3-8.

\section{NOTE}

1. We should like to acknowledge the help we have had from the following: Julia Berryman, Linda Biddles, J. A. Darley, Ann Taylor Davies, D. MacArthur, Valerie Metcalfe, and Elizabeth Tetlow.

\title{
Pemoline and magnesium hydroxide (PMH): Performance enhancement after ECS
}

\section{N. PLOTNIKOFF, Department of Pharmacology, Abbott Laboratories, North Chicago, Ill. 60064}

In a double-blind study, PMH was demonstrated to enhance performance during acquisition of a conditioned avoidance response in rats following electroconvulsive shock. This antagonism of antegrade amnesia by PMH is interpreted as further evidence of enhancement of consolidation of memory processes.

Earlier studies by Plotnikoff (1966b, 1968) indicated that pemoline and magnesium hydroxide (PMH) antagonized the retrograde amnesic effects of electroconvulsive shock in rats and rabbits. As a result of our animal studies, Small, Sharpley, \& Small (1968) initiated clinical trials and recently reported that $\mathrm{PMH}$ improved aspects of learning and memory in humans receiving electroconvulsive shock trcatment. The present study attempts to provide additional experimental data that PMH also antagonizes antegrade amnesia of the earlier-reported conditioned-avoidance response in rats.

The test chamber used for all conditioning studies was described previously (Plotnikoff, 1966a). Essentially, the apparatus consisted of a wooden test chamber with a grid flooring and an escape platform placed outside the chamber (left side). Rats were placed on the grid floor through a plastic door from the right side. An acquisition trial consisted of the following 30-sec sequence: the first $15 \mathrm{sec}$ inside the chamber without shock or buzzer, followed by $10 \mathrm{sec}$ with buzzer, and finally, $5 \mathrm{sec}$ with buzzer and shock. The intertrial interval was $8.12 \mathrm{~min}$.

Male Sprague-Dawley rats (Charles River Laboratories), weighing approximately 220-250 g, were used in these experiments. PMH, suspended in $0.3 \%$ tragacanth, was given orally. Thirty minutes after medication, electroshock was administered via corneal electrodes $(150 \mathrm{~mA}, 0.4 \mathrm{sec}$, Wahlquist apparatus), which produced maximal tonic-clonic convlusions. No significant alteration of maximal seizures was observed in PMH-treated animals. Fifteen minutes after electroshock, the animals' performance was measured in 10 acquisition trials in the jump-out test. All studies were conducted on a double-blind basis and represent the pooled sample of two studies.

The results, expressed as mean latencies of jump-out time from the test apparatus following electroshock, can be seen in Table 1. Rats pretreated with PMH at doses of 10 to $40 \mathrm{mg} / \mathrm{kg}$ had significantly shorter mean jump-out latencies compared to control animals. In addition, the trial number in which animals reached criteria of acquisition was significantly shorter for

Table 2

Mean Latencies of Jump Out Times of Rats After Electroconvulsive Shock

\begin{tabular}{ccccc}
$\begin{array}{c}\text { Trial } \\
\text { Number }\end{array}$ & $\begin{array}{c}\text { Controls } \\
(\mathbf{N}=40)\end{array}$ & $\begin{array}{c}\text { PMH 10 mg/kg } \\
(\mathbf{N}=20)\end{array}$ & $\begin{array}{c}\text { PMH 20 mg/kg } \\
(\mathbf{N}=20)\end{array}$ & $\begin{array}{c}\text { PMH 40 mg/kg } \\
(\mathbf{N}=20)\end{array}$ \\
\hline 1 & $30.0 \pm 0.0$ & $29.7 \pm 0.2$ & $29.9 \pm 0.1$ & $29.9 \pm 0.1$ \\
2 & $27.9 \pm 0.3$ & $26.9 \pm 0.7$ & $25.6 \pm 1.4$ & $25.3 \pm 1.3$ \\
3 & $22.6 \pm 1.3$ & $16.7 \pm 2.3$ & $17.4 \pm 2.2$ & $11.8 \pm 1.8^{*}$ \\
4 & $19.5 \pm 1.4$ & $17.3 \pm 2.4$ & $13.6 \pm 2.0^{*}$ & $9.3 \pm 1.7$ \\
5 & $19.4 \pm 1.3$ & $15.3 \pm 1.9$ & $12.8 \pm 2.1$ & $10.3 \pm 2.2$ \\
6 & $18.2 \pm 1.4$ & $13.5 \pm 1.7^{*}$ & $12.7 \pm 1.9$ & $11.7 \pm 1.9$ \\
7 & $18.3 \pm 1.2$ & $13.1 \pm 1.9$ & $13.1 \pm 1.8$ & $11.6 \pm 2.1$ \\
8 & $17.5 \pm 1.3$ & $16.1 \pm 2.0$ & $10.7 \pm 1.8$ & $9.4 \pm 1.6$ \\
9 & $15.6 \pm 1.3$ & $14.4 \pm 1.9$ & $10.2 \pm 1.6$ & $9.7 \pm 2.1$ \\
10 & $14.4 \pm 1.2^{*}$ & $12.8 \pm 1.8$ & $9.0 \pm 1.4$ & $8.0 \pm 1.2$ \\
\hline
\end{tabular}

* Trial reaching mean criteria of acquisition (15 sec or less)
Table 1

Double-Blind Studies of Acquisition Following Electroshock on the Jump Out Test

\begin{tabular}{ccc}
$\begin{array}{c}\text { PMH Oral Dose } \\
\text { (mg/kg) }\end{array}$ & $\begin{array}{c}10 \text { Acquisition Trials } \\
\text { Mean Latency } \\
\pm \text { S.E. (Sec) }\end{array}$ & $\begin{array}{r}\text { No. of } \\
\text { Rats }\end{array}$ \\
\hline Controls (No. ECS) & $14.6 \pm 0.8$ & 20 \\
Controls (with ECS) & $20.2 \pm 0.6$ & 40 \\
5 & $18.5 \pm 0.9$ & 20 \\
10 & $17.6 \pm 0.8^{*}$ & 20 \\
20 & $15.5 \pm 0.9^{*}$ & 20 \\
40 & $13.7 \pm 0.9^{*}$ & 20 \\
\hline
\end{tabular}

* Significant differences from controls at Duncan's multiple range test $p<0.05$ lone way analysis of variance for all groups: $F$ ration 11:05, $F$ of $.05=2.46)$.

PMH-pretreated animals (Table 2). Thus, control animals only reached acquisition criterion (mean of $15 \mathrm{sec}$ or less) by the ninth trial, whereas PMH-pretreated animals reached acquisition criterion by the third trial at a dose of $40 \mathrm{mg} / \mathrm{kg}$ and by the fourth trial at a dose of $20 \mathrm{mg} / \mathrm{kg}$.

The data clearly show that PMH effectively antagonizes the antegrade amnesic effects of electroconvulsive shock, evidenced by a significant shortening of the mean jump-out time as well as by the number of acquisition trials to criteria. Since the intertrial interval in this study was approximately $10 \mathrm{~min}$ and the total test period was $2 \mathrm{~h}$ after ECS, there is significant indication that PMH enhances consolidation processes of short-term memory. Earlier studies indicated that PMH enhanced consolidation processes when PMH was administered after training (Plotnikoff, 1967; Doty \& Howard, 1968). This enhancement effect of PMH on consolidation of memory processes may be mediated by improved synaptic transmission in the central nervous system (Plotnikoff, 1968).

\section{REFERENCES}

DOTY, B., \& HOWARD, S. Facilitative effects of post-trial magnesium pemoline on avoidance conditioning in relation to problem difficulty. Life Sciences, 1968, 7, 591-597.

PLOTNIKOFF, N. Magnesium pemoline: Enhancement of learning and memory of a conditioned avoidance response. Science, 1966a, 151, 703-704.

PLOTNIKOFF, N. Magnesium pemoline: Enhancement of memory after electroconvulsive shock in rats. Life Sciences, $1966 \mathrm{~b}, 5,1495-1498$.

PLOTNIKOFF, N. Pémoline and magnesium hydroxide: Memory consolidation following acquisition trials. Psychonomic Science, 1967, 9, 141-142.

PLOTNIKOFF, $N$. Learning and memory enhancement by pemoline and magnesium hydroxide (PMH). In J. Wortis (Ed.), Recent advances in biological psychiatry. Vol. X. New York: Plenum Press, 1968. Chap. 9.

SMALL, I. F., SHARPLEY, P., \& SMALL, J. G. Influences of Cylert upon memory changes with ECT. American Journal of Psychiatry, $1968,125,149-152$. 